\title{
Multicriteria Evaluation of Flood Control Measures: The Case of Ribeira do Livramento
}

\author{
Carlos A. Bana e Costa ${ }^{1,2}$ \\ Paula Antão da Silva ${ }^{3}$ \\ Francisco Nunes Correia ${ }^{1}$ \\ ${ }^{1}$ Instituto Superior Técnico, Technical University of Lisbon, Lisbon \\ ${ }^{2}$ Department of Operational Research, London School of Economics \\ ${ }^{3}$ Laboratório Nacional de Engenharia Civil, Lisbon
}


First published in Great Britain in 2003

by the Department of Operational Research

London School of Economics and Political Science

Copyright (C) The London School of Economics and Political Science, 2003

The contributors have asserted their moral rights.

All rights reserved. No part of this publication may be reproduced, stored in a retrieval system, or transmitted in any form or by any means, without the prior permission in writing of the publisher, nor be circulated in any form of binding or cover other than that in which it is published.

Typeset, printed and bound by:

The London School of Economics and Political Science

Houghton Street

London WC2A 2A 


\title{
Multicriteria Evaluation of Flood Control Measures: The Case of Ribeira do Livramento
}

\author{
Carlos A. Bana e Costa ${ }^{1,2}$ \\ Paula Antão da Silva ${ }^{3}$ \\ Francisco Nunes Correia ${ }^{1}$ \\ ${ }^{1}$ Instituto Superior Técnico, Technical University of Lisbon, Lisbon \\ ${ }^{2}$ Department of Operational Research, London School of Economics \\ ${ }^{3}$ Laboratório Nacional de Engenharia Civil, Lisbon
}

This paper describes the multicriteria process used to evaluate flood control options for the catchment of Livramento creek in the peninsula of Setúbal, in Portugal. In the structuring phase, the environmental, social, and technical dimensions were identified. The MACBETH approach - Measuring Attractiveness by a Categorical Based Evaluation Iechnique - was then used to construct a quantitative evaluation model based on qualitative value judgments formulated by a group of experts from different technical and scientific fields. The model enabled the overall benefit associated with each option to be appraised, and extensive sensitivity analyses to be performed.

Keywords: Multicriteria analysis, MACBETH, Flood control measures, Environmental impact assessment. 


\section{Introduction}

Decision-making processes involving the use of public resources usually require a wellinformed, well-justified and consistent analysis of the costs and benefits associated with potential future courses of action. This was the case in the multicriteria evaluation process of the flood control measures for the catchment of Livramento creek in the peninsula of Setúbal, in Portugal, which will hereafter be referred to as the "Livramento case". Some relevant background information about the context of the Livramento case is provided in section 2.1. The core concern was to minimise the effects of the floods on the environment and society, through a technically appropriated intervention, at reasonable and realistic investment costs. For this purpose, alternative interventions had previously been developed by technical consultants on behalf of the municipality of Setúbal, as described in section 2.2. An overview of the steps involved in the multicriteria evaluation process of those options is offered in section 3. Sections 4 and 5 detail the application, conducted by the authors of this paper in strict interaction with various experts, who provided the necessary judgemental information. Their technical and scientific backgrounds were: surface and underground hydrology, soil deterioration, biology, landscape architecture, environmental sociology and environmental economics. Some conclusive reflections about the case are the subject of section 6.

\section{The Livramento case}

\subsection{Scope and background information}

Located on Portugal's Atlantic coast, in the estuary of the river Sado, Setúbal is a mediumsized town that has grown up on the floodplain of several watercourses. Heavy rainfalls of short duration, with a recurrence interval of about 15 years have often led to major floods causing serious material damage in its downtown area. Moreover, as Setúbal has expanded through the valley and the floodplain, lower amplitude floods have begun to affect certain sections of the town's lowest area on an almost yearly basis. The catchment areas of streams in particular the Ribeira do Livramento (Livramento creek), $8 \mathrm{~km}$ in length, with an area of $12.8 \mathrm{~km}^{2}$ - have very steep slopes in the upstream zone and a high percentage of soil with low water-retention capacity. They drain an area with a fan-like configuration, thus producing high magnitude flows, the rain converging and concentrating downtown.

These natural conditions have been made worse by human intervention: the increasing occupation and imperviousness of the soils in the catchment areas by urbanization and various other types of infrastructure, led to an increase in runoff and flood volumes; deforestation and quarrying aggravated erosion and caused bed load transport downstream; and, waste material accumulated in the watercourses as a result of silting and the defective discharge capacity of the town's storm sewers into which the flows from streams are discharged ( $c f$. Hidroquatro, 1992). Moreover, a riverside avenue that runs parallel to the coastline exists in Setúbal, whose embankment was constructed at a higher level than downtown; it, therefore, operates as a dike and obstructs the surface discharge into the estuary of the river Sado. Lastly, the runoff conditions of the streams are very often worsened by adverse tidal conditions. The 1994 Municipal Land-Use Master Plan of Setúbal did not succeed in correcting old urban development mistakes and regulating construction by private promoters; furthermore, it still included an urban expansion zone. 
Subsequent to the severe 1983 floods, several hydrological studies were carried out. The flood regime was characterized, the hydraulic runoff conditions were analysed and the areas involving flood hazard were mapped. In 1996, as part of the EUROflood Research Project The Europe-wide Project for Flood Hazard Research and Policy Making (Penning-Rowsell and Fordham, 1994; Penning-Rowsell, 1997) - the Portuguese sub-project, The Planning of Flood Measures: Interface with the Public (Correia et al., 1996), dealt with some aspects of the Livramento problem: hydrological and hydraulic flood models were studied as part of the comprehensive approach to floodplain management and coupled to a Geographic Information System (GIS) in which different flood scenarios were analysed (Correia et al., 1998a). Particular emphasis was given to the public perception of, and response to, natural floods (Correia et al., 1998b). Recommendations for flood hazard management and policy-making arose from the project. Among these recommendations was the conclusion that a GIS linked to hydrological and hydraulic modelling functionalities could be very useful in land-use management. It would be particularly appropriate in a participatory approach to flood policy formulation and floodplain management, facilitating communication with the public in a scientifically accurate and yet reasonably simple way. With such a tool, not only can the existing situation be represented and flooding scenarios explored, but the consequences of urban growth scenarios can also be anticipated. This is especially important in urban areas where some of the most critical flood problems occur, the monetary values at risk are higher, and damage tends to be heavier (Correia et al., 1999a and b).

The cost-benefit multicriteria analysis of alternative flood control interventions in the Ribeira do Livramento was performed as part of the EUROflood project (cf. Antão da Silva, 1996), as described hereafter.

\subsection{The flood control options}

The technical consultants, on behalf of the municipality of Setúbal, defined an intervention area of about 20 ha of the catchment area of the creek, which included the last non-piped stretch of the stream. They then developed two structural flood control solutions (A1 and A2), and a "minimal-intervention" (A0). A0 served as a reference point for the appraisal of the marginal benefits of $\mathrm{A} 1$ and $\mathrm{A} 2$. These were the three options subject to the multicriteria analysis; they can be briefly described as follows:

A0 The continuation of urban development in the same way as in the preceding years. No flood control measures are to be adopted, except the prevention of new construction and periodic maintenance of the bed and banks. The net present value (NPV) of the total cost (investment and maintenance) of A0 was estimated to be $€ 31,000$.

A1 Option A1 consists of (see Figure 1): (1) the construction of a retention basin, in the intervention area, aimed at baffling the flood flows discharged into the Livramento creek, whose recurrence period is less than 100 years; (2) the regularisation of the section of the stream included in the retention basin; (3) the construction of a sedimentation basin to retain upstream sediments, thus avoiding the silting of the downstream sewer. When periodic cleaning is carried out, this system increases the discharge capacity of the hydrographical network. A1 serves only hydraulic purposes and does not address either urban integration or the enhancement of the landscape. The NPV of the total cost of A1 was estimated to be $€ 1,600,000$. 


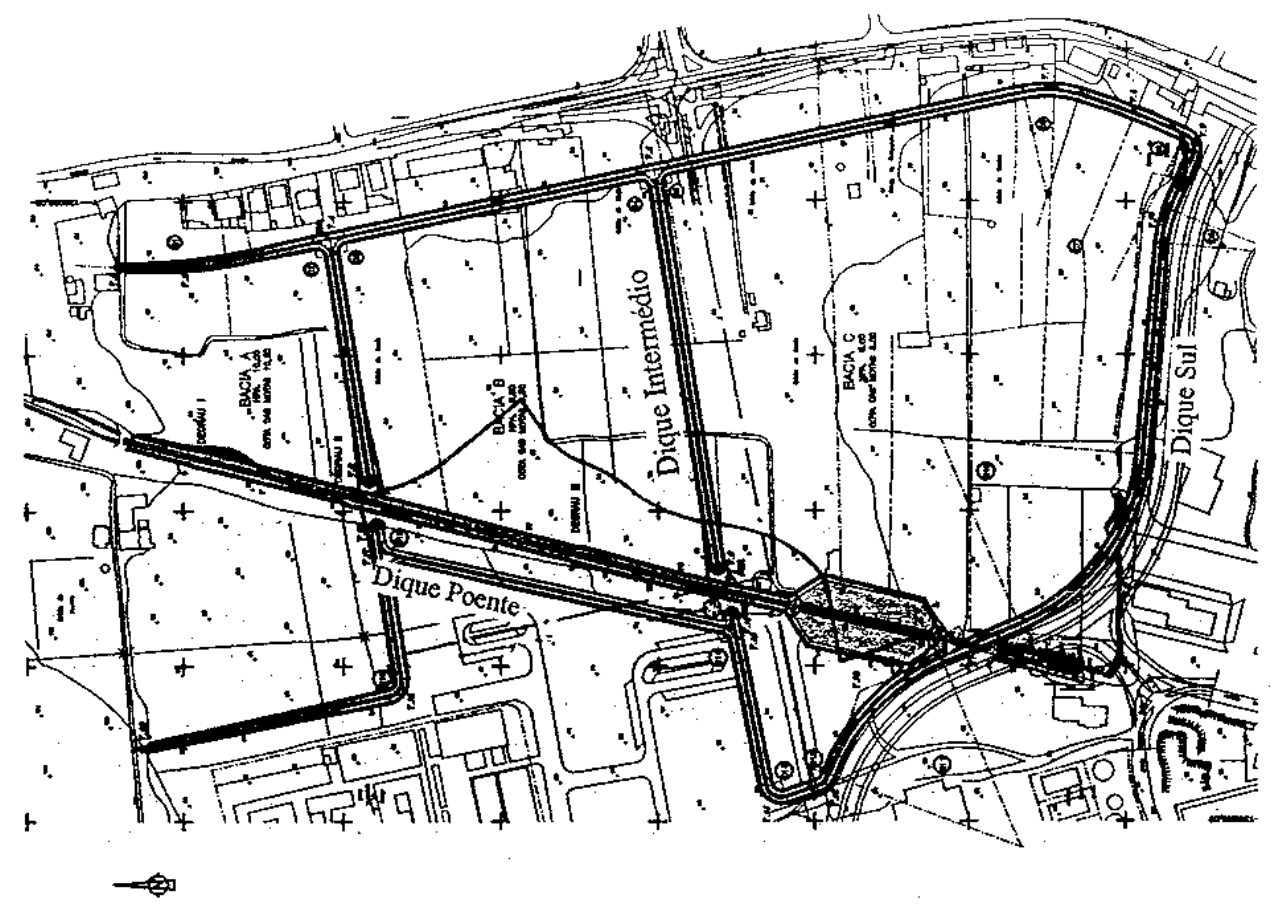

Figure 1. Scheme of intervention option A1.

A2 Option A2 (see Figure 2) is similar to A1 from a hydraulics point of view; however, it includes the construction of an urban park designed to disguise the hydraulic structures and to improve the surrounding urban area both aesthetically and socially. The NPV of the total cost of A2 was estimated to be $€ 4,600,000$.

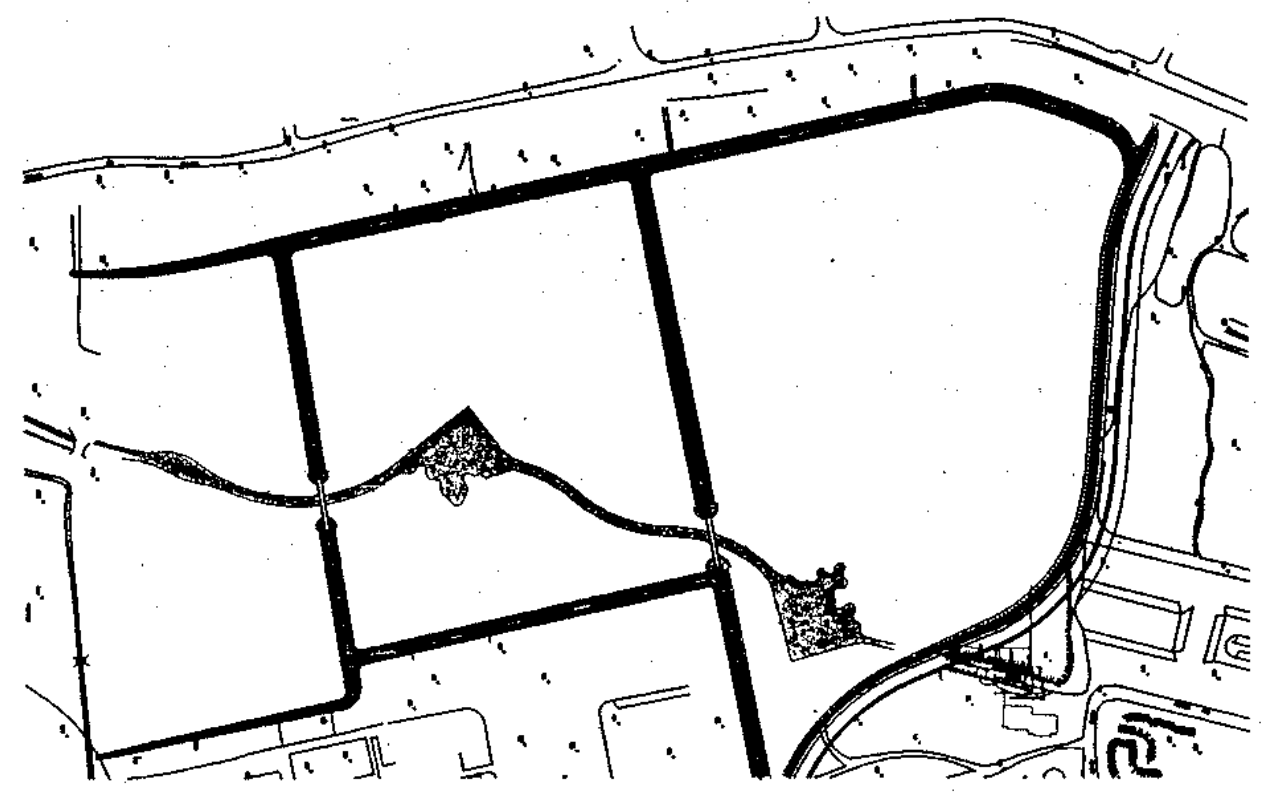

Figure 2. Scheme of intervention option A2. 


\section{The methodology}

\subsection{Steps of the application}

The adoption of a multiple criteria decision analysis (MDCA) approach to evaluate the options was intimately influenced by the following two convictions as fundamental pillars of good decision-aiding practice ( $c f$. Bana e Costa and Pirlot, 1997):

$\checkmark$ The conviction that the objective and subjective elements of a decision context are interconnected and inseparable: a decision process is a system of relationships between elements of an objective nature (e.g., the characteristics of the options) and elements of a subjective nature (stemming both from the value systems of the actors and the ill-defined decision context). These types of elements are intricately linked and neither can be neglected in decision support. Although the search for objectivity must be of great concern, one must not forget that decision-making is above all a human activity subtended by the notion of value. Subjectivity is omnipresent in decision-making, one must, therefore, recognise the limits of a purely objective approach.

$\checkmark$ The conviction of constructivism and learning: a decision situation is, in general, an illdefined entity, unclear even to the actors involved in the decision process. A constructivist methodological approach is therefore most appropriate for decision-aiding, in light of the modern paradigm of learning and requisite modeling, that should replace the "old" paradigm of normative optimisation. A direct implication of the adoption of a constructivist attitude in decision-aid is that simplicity and interaction are fundamental tools for effective participation.

Technically, the multicriteria decision aid process applied to the Livramento case can be described as a package of activities (see Figure 3) grouped into three main phases of analysis: structuring, evaluation, and the elaboration of recommendations which was developed throughout the process. The structuring phase included the activities related to problemstructuring, model-structuring and impact assessment. In more detail:

- In problem structuring, as addressed in section 2, the decision context was analysed, its boundaries were fixed and the actors involved were identified, the core objectives and the options to achieve them were defined. The key question for problemstructuring was "What is the Problem?" (cf. Rosenhead, 1996), and, in line with Watson and Buede (1987), at the end of this activity we were in "a position after learning the above information to suggest and describe to the decision-maker the benefits that an analytic strategy will have."

- Model structuring consisted of interviews with the experts, in order to identify the key benefit concerns for the analysis; this permitted the benefit dimensions of the analysis to be structured in the value-tree of Figure 4 and descriptors to be constructed in order to specify the impacts of the options (see section 4.1).

- Impact assessment and analysis consisted of, first, estimating the consequences of implementing an option. This enabled an appraisal of the pros and cons of the flood control measures to be performed, for each dimension of analysis, through a comparison with the reference option A0 (see section 4.2).

This qualitative assessment stage was very useful as it helped to draw meaningful conclusions and to produce recommendations for the decision. Nevertheless, the impact analysis did not provide a measurement of each option's overall benefit; for this, a quantitative value model was required. This model, along with the sensitivity analyses of its outputs, were the core of the evaluation phase of the process (section 5): 
PROBLEM STRUCTURING (section 2)

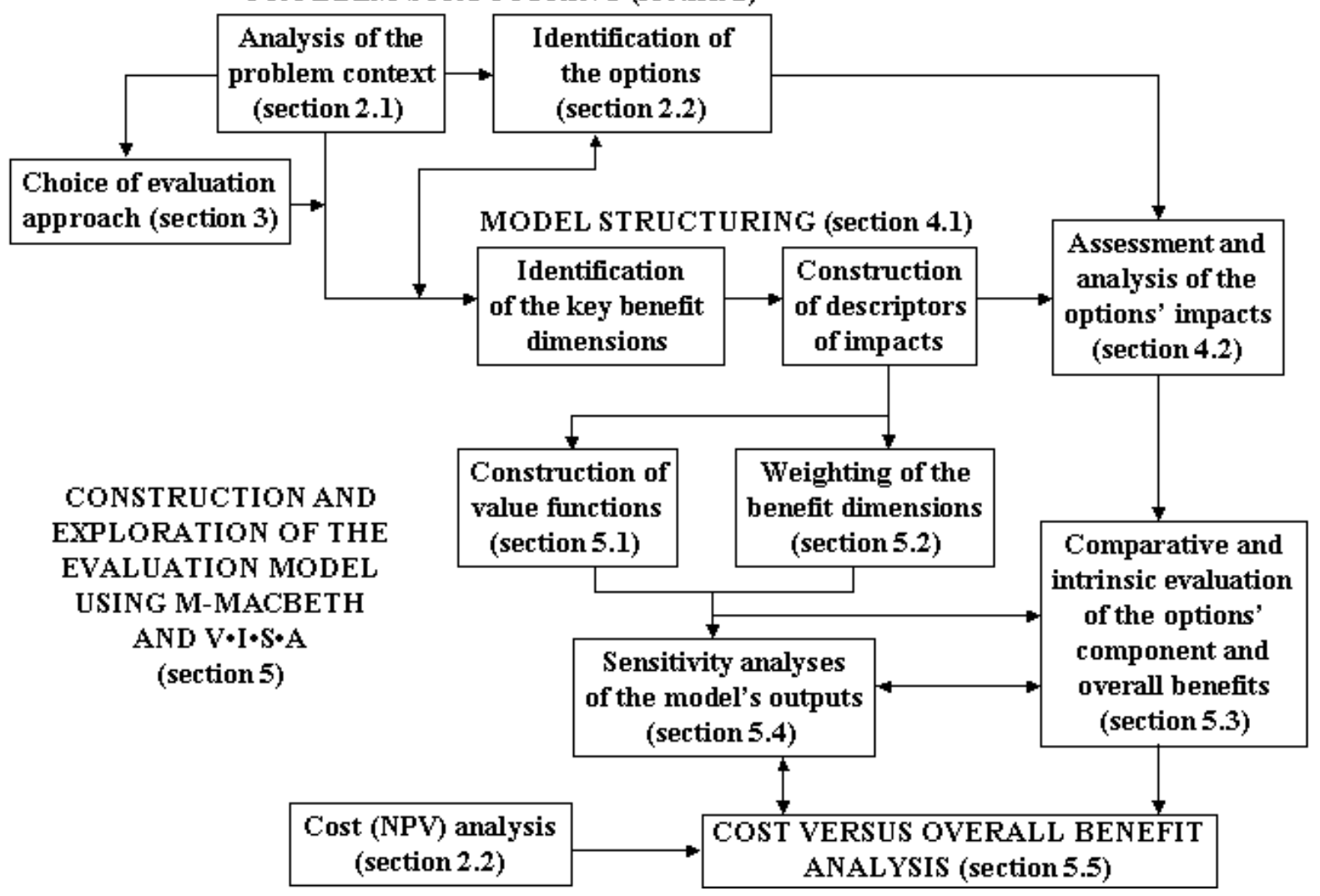

Figure 3. Schematical overview of the activities of the multicriteria value analysis.

- The construction of a quantitative model of values involved the interactive construction, conducted with the panel of experts, of a hierarchical additive valuemodel, making use of the MACBETH approach to, both, construct a value function for each of the benefit dimensions (see section 5.1) and to weight them (see section 5.2).

- Options-evaluation consisted of applying the model, with the support of the $\mathrm{V} \cdot \mathrm{I} \bullet \mathrm{S} \bullet \mathrm{A}$ software, to each of the options, in order to compare them and analyse their intrinsic and relative attractiveness, that is, the extent to which a particular option was strong or weak and by how much one option was more or less attractive than another, both with regard to each group (component) of benefit dimensions and in overall terms (see section 5.3).

- Sensitivity analyses (see section 5.4) explored the extent to which the variation of certain parameters of the model, namely the weights of the criteria, would affect the conclusions drawn from it. This was essential to guarantee that the evaluation model constructed was a "requisite model" ( $c f$. Phillips, 1984).

Once a measure of the overall benefit of each of the options was determined, a cost-benefit graphical analysis could finally be produced (see section 5.5). This provided the basis to debate the extent to which the implementation of one option rather than another would be worthwhile. 


\subsection{Sequential use of $M-M A C B E T H$ to build the model and $V \cdot I \bullet S \bullet A$ to exploit it}

Extensive literature exists devoted to Multicriteria Decision Analysis (MCDA), and in particular to Multicriteria Value Analysis: comprehensive descriptions and applications of value function methods and techniques are offered by, among many others, von Winterfeldt and Edwards, 1986; Watson and Buede, 1987; Kirkwood, 1996; Beinat, 1997; Belton and Stewart, 2002. MACBETH (Measuring Attractiveness by a Categorical Based Evaluation Technique), whose mathematical foundations are updated in (Bana e Costa et al., 2004), was the multicriteria approach adopted in the Livramento case to construct an additive value model that served to guide the evaluation and the comparison of the alternatives against the multiple benefit dimensions. All of the activities that formed the evaluation phase of a MCDA process can today be performed in an integrated way, with the support of either the M-MACBETH software (see Bana e Costa et al., 2003 and www.m-macbeth.com), or the HIVIEW3 software (see Catalyze, 2003) for hierarchical additive models. However, at the time of the Livramento case, these two software packages were not available in their current versions. Therefore, the outputs of the MACBETH analysis, which was developed with the support of the version of the M-MACBETH software available at that time, were subsequently used to build a comprehensive hierarchical additive value model in the $\mathrm{V} \cdot \mathrm{I} \cdot \mathrm{S} \cdot \mathrm{A}$ software (Visual Interactive Sensitivity Analysis). Moreover, the use of $\mathrm{V} \cdot \mathrm{I} \cdot \mathrm{S} \bullet \mathrm{A}$, a powerful and user-friendly multicriteria decision support tool conceived by Belton and Vickers (1990) (see also Belton, 1999), had the advantage of facilitating the sensitivity analysis required of the model's results.

One distinctive characteristic of the MACBETH approach is its use of a straightforward interactive questioning process, which requires only qualitative judgements about differences of value to help an individual, or a group, weight criteria and quantify the relative attractiveness of options in each criterion. This can be done either through a direct comparison of the options (see example in Bana e Costa et al., 2002) or through the construction of value functions (see examples in Bana e Costa and Vansnick, 1997 and 1999; Bana e Costa, 2001) as was done in the Livramento case. Asking only for qualitative judgemental information enables one to avoid, as remarked by Belton and Stewart, 2002 and Bana e Costa and Chagas (2004), potential difficulties that may arise either when evaluators are forced to produce direct numerical estimations of values and weights, as required by numerical methods such as SMART, the Simple Multi-Attribute Rating Technique (cf. Edwards, 1971; von Winterfeldt and Edwards, 1986; Edwards and Barron, 1994), or when more traditional utility assessment techniques are used (an application in the context of water resource planning can be found in Keeney and Wood, 1977).

\section{Model structuring and impact assessment 4.1. Structuring the benefit dimensions of analysis}

The potential benefits of implementing each of the three options described in section 3.2 were first assessed for each of the benefit dimensions at the lower level of the value tree represented in Figure 4. This tree was structured according to the points of view of the various experts; it provided an organised overview of these views with several levels of specificity. During the interview process, and apart from the cost dimension, the experts emphasised three non-economic components: environmental impacts, in particular those regarding hydrological concerns and aspects related to the alternatives' integration into the 
urban landscape; social impacts, with special attention being paid to the public health factor; and the technical efficiency of the alternative solutions.

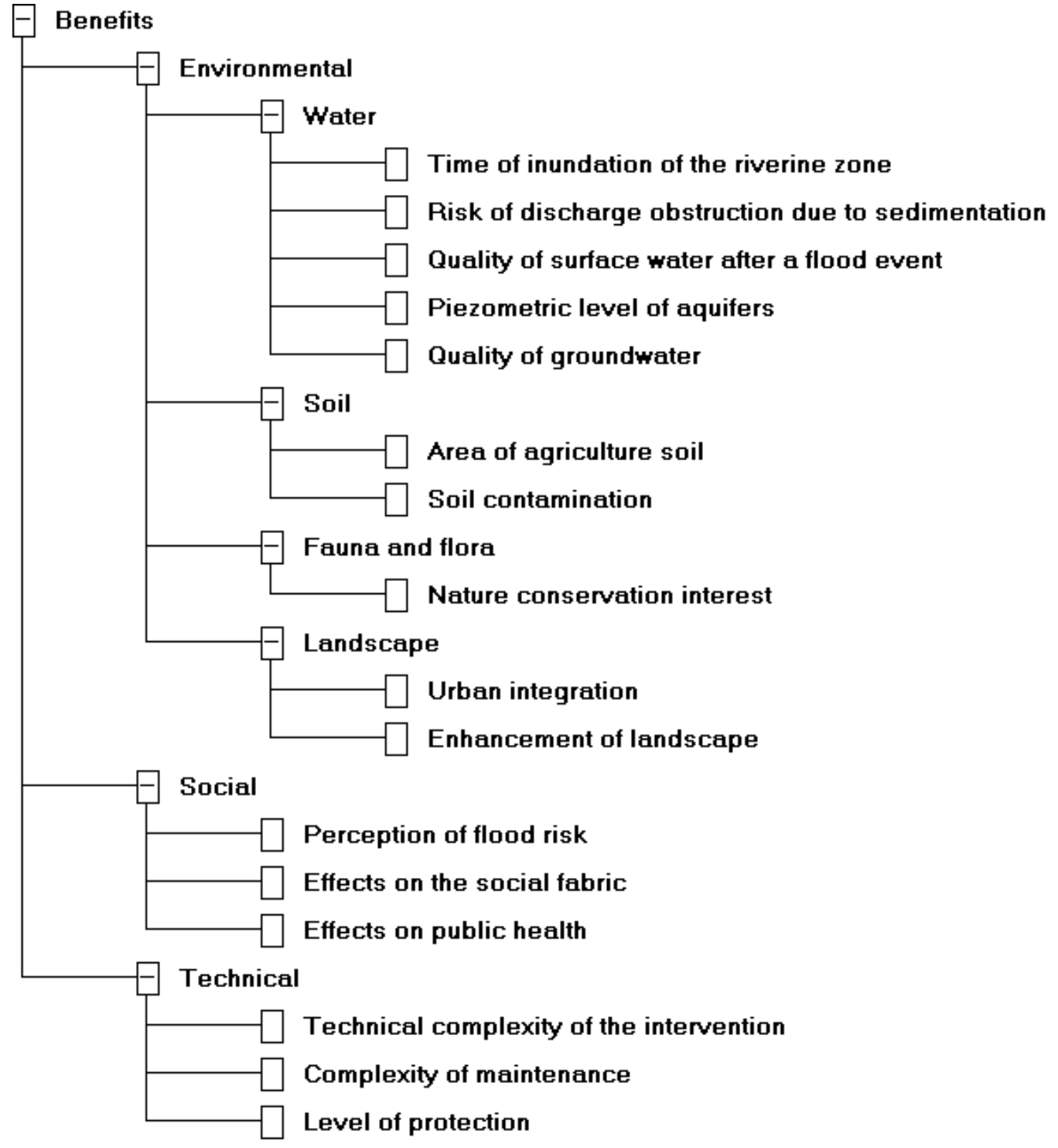

Figure 4. Benefits' value tree.

For each of the 16 benefit dimensions, a quantitative or qualitative "descriptor" of impacts (sometimes referred to as an "attribute" - see Keeney, 1992), that is an ordered set of plausible impact levels, was defined by, or constructed with, the experts. The construction of descriptors, or attributes, some times alternatively called "the construction of criteria" (cf. Bouyssou, 1990; Azibi and Vanderpooten, 2003) was a very important structuring activity, during which several multiple elementary interdependent consequences had to be aggregated to form a single descriptor. This was done to guarantee the additive preferential independence of the benefit dimensions, necessary to accept each of them as an evaluation criterion in the model. For example, Table 1 shows the seven-level scale constructed to qualitatively appraise the level of risk of discharge obstruction due to sedimentation; four interrelated consequences of the implementation of the flood control measures were combined: whether sedimentation was, or was not, expected to occur, in the sewer, in the retention basin or in the channel, and if the system was consider to be balanced. 
Table 1. Qualitative descriptor of "risk of discharge obstruction due to sedimentation".

(The impact levels are numbered in decreasing order of relative attractiveness, that is, $L x$ is more attractive than Ly if and only if $x>y$.)

\begin{tabular}{cl}
\hline Impact level & Description of the impact level \\
\hline L1 & $\begin{array}{l}\text { If the option under analysis is implemented: } \\
\text { No significant sedimentation is expected to occur in the sewer, in the retention basin or in } \\
\text { the channel. }\end{array}$ \\
L2 & $\begin{array}{l}\text { Sedimentation may occur both in the sewer and the channel, but it is not expected to occur } \\
\text { in the retention basin. }\end{array}$ \\
L3 & $\begin{array}{l}\text { Sedimentation may occur both in the sewer and the retention basin, but it is not expected } \\
\text { to occur in the channel. }\end{array}$ \\
L4 & $\begin{array}{l}\text { Sedimentation may occur in the sewer, but it is not expected to occur either in the channel } \\
\text { or in the retention basin. }\end{array}$ \\
L5 & $\begin{array}{l}\text { Sedimentation may occur in the channel, but it is not expected to occur either in the sewer } \\
\text { or in the retention basin. }\end{array}$ \\
L6 & $\begin{array}{l}\text { Sedimentation may occur in the retention basin, but it is not expected to occur either in the } \\
\text { sewer or in the channel. } \\
\text { Sedimentation may occur in the sewer, in the channel, and in the retention basin. The } \\
\text { system is balanced. }\end{array}$ \\
L7
\end{tabular}

\subsection{Impact analysis}

Determining the level of each of the sixteen descriptors for each of the alternatives enabled each alternative's benefit impact-profile to be defined. Comparing the impact-profiles associated with structural options A1 and A2 with the minimal-intervention A0 provided qualitative knowledge as to their positive and negative added benefits. Table 2 illustrates this analysis.

Table 2. Qualitative benefit analysis: positive $(+)$ and negative $(-)$ added benefits of implementing either A1 or A2, relative to the impacts of the minimal intervention A0.

\begin{tabular}{lcc}
\hline Benefit dimension & Option A1 & Option A2 \\
\hline Environmental component: & & \\
Time of inundation of the riverine zone & + & + \\
Risk of discharge obstruction due to sedimentation & + & + \\
Quality of surface water after a flood event & + & + \\
Piezometric level of aquifers & + & + \\
Quality of groundwater & - & - \\
Area of agriculture soil & - & - \\
Soil contamination & $=\mathrm{A} 0$ & + \\
Nature conservation interest & - & - \\
Urban integration & + & + \\
Enhancement of landscape & - & + \\
Social component: & & \\
Perception of flood risk & + & + \\
Effects on the social fabric & - & + \\
Effects on public health & - & - \\
Technical component: & & \\
Technical complexity of the intervention & + & + \\
Complexity of maintenance & + & + \\
Level of protection & + & + \\
\hline
\end{tabular}


Four environmental and two social dimensions exist for which the consequences of option A1 are worth less than those of the minimal intervention A0. Note also that option A2 dominates option A1 in terms of benefits, that is, the impact of A2 in each of the benefit dimensions is at least as attractive as the corresponding impact of A1. This is not at all surprising, since A2 was developed as an improvement of A1, specifically in terms of enhanced landscape, as can be seen in Table 2, as well as the impact on the social fabric. Nevertheless, the extent to which option A2 is more attractive that A1, both in terms of the aggregate benefit in each component and overall benefit, could be appraised only after the construction of a multicriteria hierarchical additive value model. This was also important for a final trade-off analysis between the additional cost of implementing $\mathrm{A} 2$, rather than only $\mathrm{A} 1$, and the increase in the overall benefit that doing so would provide.

\section{The evaluation phase}

\subsection{Construction of a value function for each benefit dimension with MACBETH}

As previously mentioned, a (cardinal) value function was constructed in order to enable the quantification of the relative attractiveness of the options in regards to each of the sixteen benefit dimensions. The value functions were derived from qualitative value judgments formulated by the expert in each respective area. The MACBETH assessment procedure was adopted for this purpose.

Take for instance the concern "risk of discharge obstruction due to sedimentation" and its descriptor in Table 1. The MACBETH question-answer protocol consisted of asking the assessor if, for each pair of impact levels $\mathrm{Lx}$ and Ly (with $\mathrm{x}>\mathrm{y}$ ), the difference of attractiveness between Lx and Ly was: very weak, weak, moderate, strong, very strong, or extreme (MACBETH's semantic categories). Each time a judgment was formulated, the MMACBETH software automatically tested the consistency of all of the judgments already formulated and pointed out any situations of inconsistency. Figure 5 shows the final matrix of the expert's qualitative judgments and the corresponding MACBETH value scale proposed by the software. (The MACBETH scale is determined by linear programming, as detailed in Bana e Costa et al., 2003). As can be seen in the matrix of judgements, the expert regarded the difference in attractiveness between L7 and L6 to be very weak, while the difference in attractiveness between any other consecutive pair of levels to be, always, weak; note also the particular linear structure of the sub-matrix formed by the judgments involving L6 to L1. This is reflected in the numerical scale by a constant difference in value from L1 to L6 and half of that difference for the "very weak" difference of attractiveness between L7 and L6. The expert accepted these proportions, thereby validating the cardinality of the scale.

A similar interactive process was used to derive value functions for all of the other dimensions. Each option's impact could then be translated into value scores that measure its relative attractiveness against each of the benefit dimensions found at the lower level of the value tree in Figure 4. 


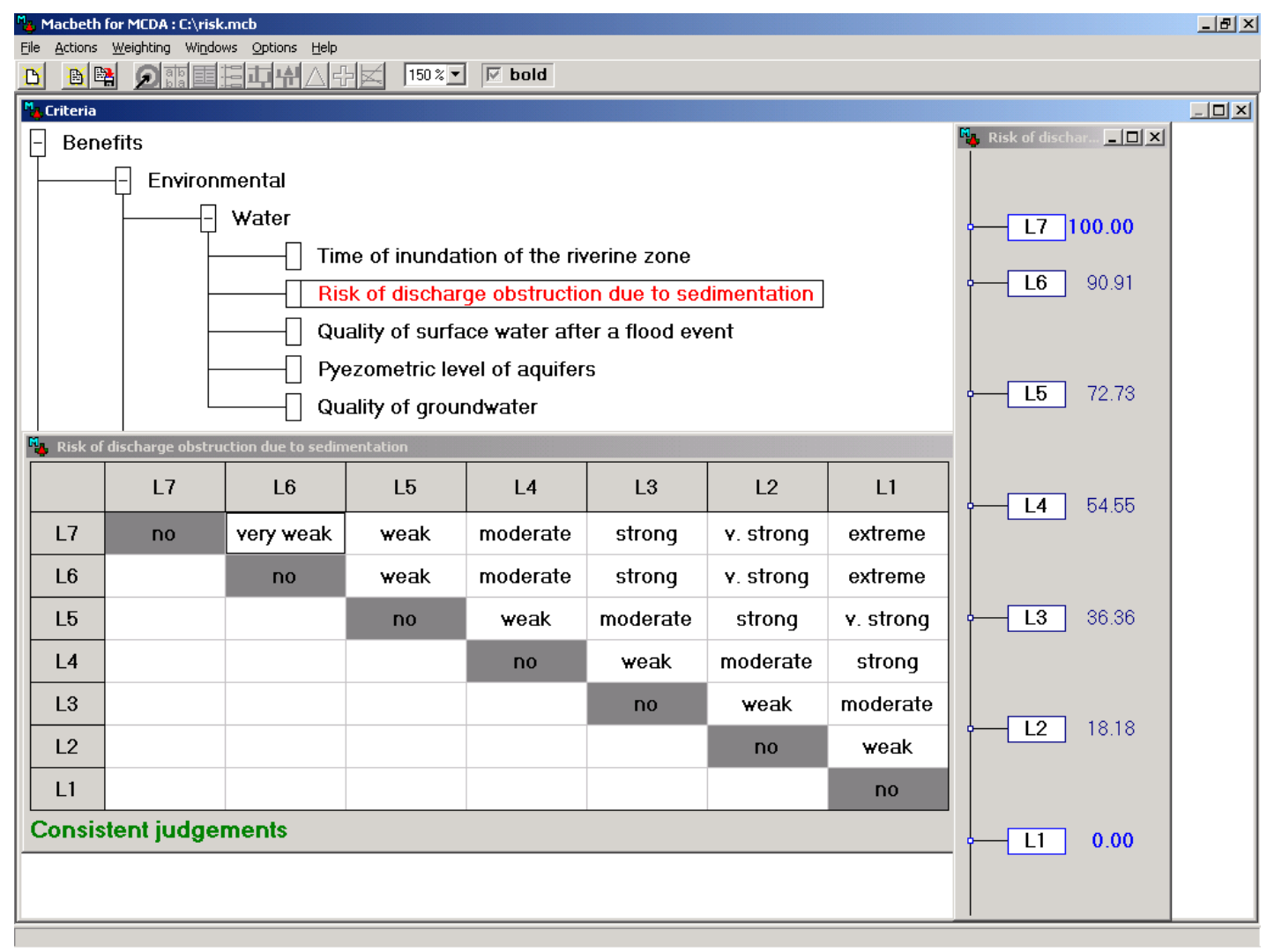

Figure 5. Using M-MACBETH to assess a value scale.

\subsection{The MACBETH weighting process}

The evaluation of an option $A$ at the component level (i.e., each group of benefit dimensions; e.g. environmental, social, etc.) required its dimensional scores to somehow be aggregated. This was performed by simple additive aggregation, carried out from bottom to top in the value tree, assuming that each dimensional score of $A$ contributes independently to its aggregated value:

$$
V_{c}(A)=V_{c}(\text { impact profile of } A)=\sum_{j=1}^{n_{c}} w_{j} \cdot v_{j}(\text { impact of } A \text { on } j)
$$

with $\sum_{j=1}^{n_{c}} w_{j}=1$ and $w_{j}>0$ and $\left\{\begin{array}{l}v_{j}(\text { most attractive impact level on } j)=100 \\ v_{j}(\text { least attractive impact level on } j)=0\end{array}\right.$

where:

$V_{c}(A)$ is the aggregate value of an option $A$ in component $C$,

$n_{c}$ is the number of benefit dimensions integrating $C$,

$v_{j}$ (impact of $A$ on $j$ ) is the value score of $A$ in $\operatorname{dimension} j$, and

$w_{j}\left(j=1\right.$ to $\left.n_{c}\right)$ are the scaling factors ("relative weights") enabling the scores $v_{j}(A)(j=$ 1 to $n_{c}$ ) to be harmonized ("weighted").

The weights were assessed using the MACBETH weighting procedure. For instance, for the "water" sub-component, which integrates five dimensions (see Figure 6), the question-answer process began with the fictitious option (the "anti-ideal" profile in Figure 7) whose impacts in 
each dimension is the least attractive level of the respective descriptor. The assessor was asked to qualitatively judge the increase in overall attractiveness provided by a swing from the least to the most attractive impact level in each of the five water dimensions. These judgments form the last column of the matrix in Figure 6. He then filled in the rest of the matrix by comparing the swings pairwise, always using the MACBETH semantic categories. The corresponding relative weights adopted are shown in the bar chart found in Figure 6.

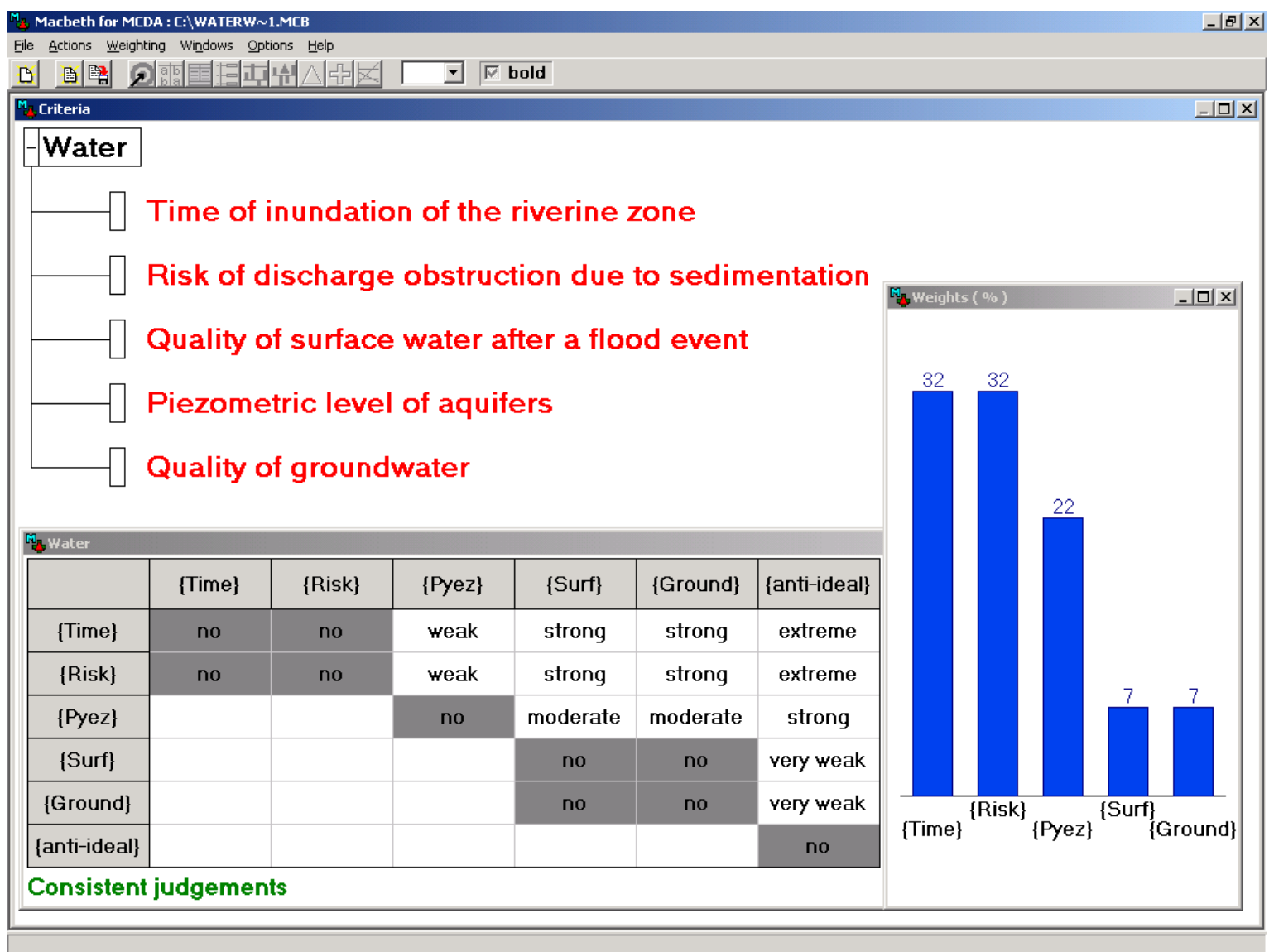

Figure 6. Weighting the dimensions within the "Water" component

Finally, the following procedure was followed for weighting the components. First, the dimensions with the greatest weight within each component were selected and relative weights for only those dimensions were determined using the MACBETH weighing process to the respective swings. The weights of all of the dimensions were then proportionally rescaled and added up within each component (see last line of Table 3 ).

\subsection{Multicriteria evaluation of the options' benefits performed with $\mathbf{V} \cdot \mathbf{I} \cdot S \cdot A$}

Using $\mathrm{V} \cdot \mathrm{I} \cdot \mathrm{S} \cdot \mathrm{A}$, the additive model could then be used hierarchically to calculate the aggregate benefit scores for the three options (see Table 3 and Figure 7) as well as to perform visual and interactive sensitivity analyses (see section 5.4). As can be seen, in terms of the overall benefit, the non-economic value of a deep intervention (either A1 or A2) would be significantly greater than opting for a minimal intervention (A0); and the increase in benefit resulting from the implementation of A2 instead of A1 would be worth 29 (=87-58) overall benefit units. A significant output favouring option A2 is its environmental benefit, which is greater than that of the minimal intervention (an environmental score of 78 versus 56); this is in contrast to what would happen if A1 were implemented (52 versus 78). 
Table 3. Aggregated benefit scores of the options

\begin{tabular}{|c|c|c|c|c|c|c|c|c|}
\hline & \multirow{2}{*}{$\begin{array}{l}\text { Overall } \\
\text { benefit } \\
\text { scores }\end{array}$} & \multicolumn{5}{|c|}{$\begin{array}{l}\text { Environmental } \\
\text { benefit scores }\end{array}$} & \multirow{2}{*}{$\begin{array}{l}\text { Social } \\
\text { benefit } \\
\text { scores }\end{array}$} & \multirow{2}{*}{$\begin{array}{c}\text { Technical } \\
\text { benefit } \\
\text { scores }\end{array}$} \\
\hline & & Water & Soil & $\begin{array}{c}\text { Fauna } \\
\text { and } \\
\text { Flora }\end{array}$ & Landscape & & & \\
\hline A0 & 37 & 55 & 29 & 78 & 60 & 56 & 22 & 0 \\
\hline $\mathrm{A} 1$ & 58 & 85 & 0 & 0 & 13 & 52 & 52 & 78 \\
\hline A2 & 87 & 91 & 36 & 0 & 86 & 78 & 96 & 100 \\
\hline Weights & & 0.57 & 0.07 & 0.09 & 0.27 & 0.57 & 0.20 & 0.23 \\
\hline
\end{tabular}

As far as the intrinsic value of each option, note that Figure 7 shows the benefit scores for a "neutral" benchmark (ANeutral) along with the scores for options A0, A1 and A2. Aneutral is a fictitious option whose impact-profile is composed entirely of neutral levels of impact (i.e., neither attractive nor unattractive consequences) in each of the sixteen benefit-dimensions. The comparison of the benefit scores of the three options with the corresponding scores of the neutral benchmark, in Figure 7, led to the conclusion that A2 is intrinsically attractive in each of the three components of the benefit analysis as well as in terms of overall benefit; on the other hand, A1 would have a positive, although small, intrinsic overall value only because, given the component relative weights, the high intrinsic technical benefit provided by A1 would be enough to compensate for its unattractive environmental and social impacts.

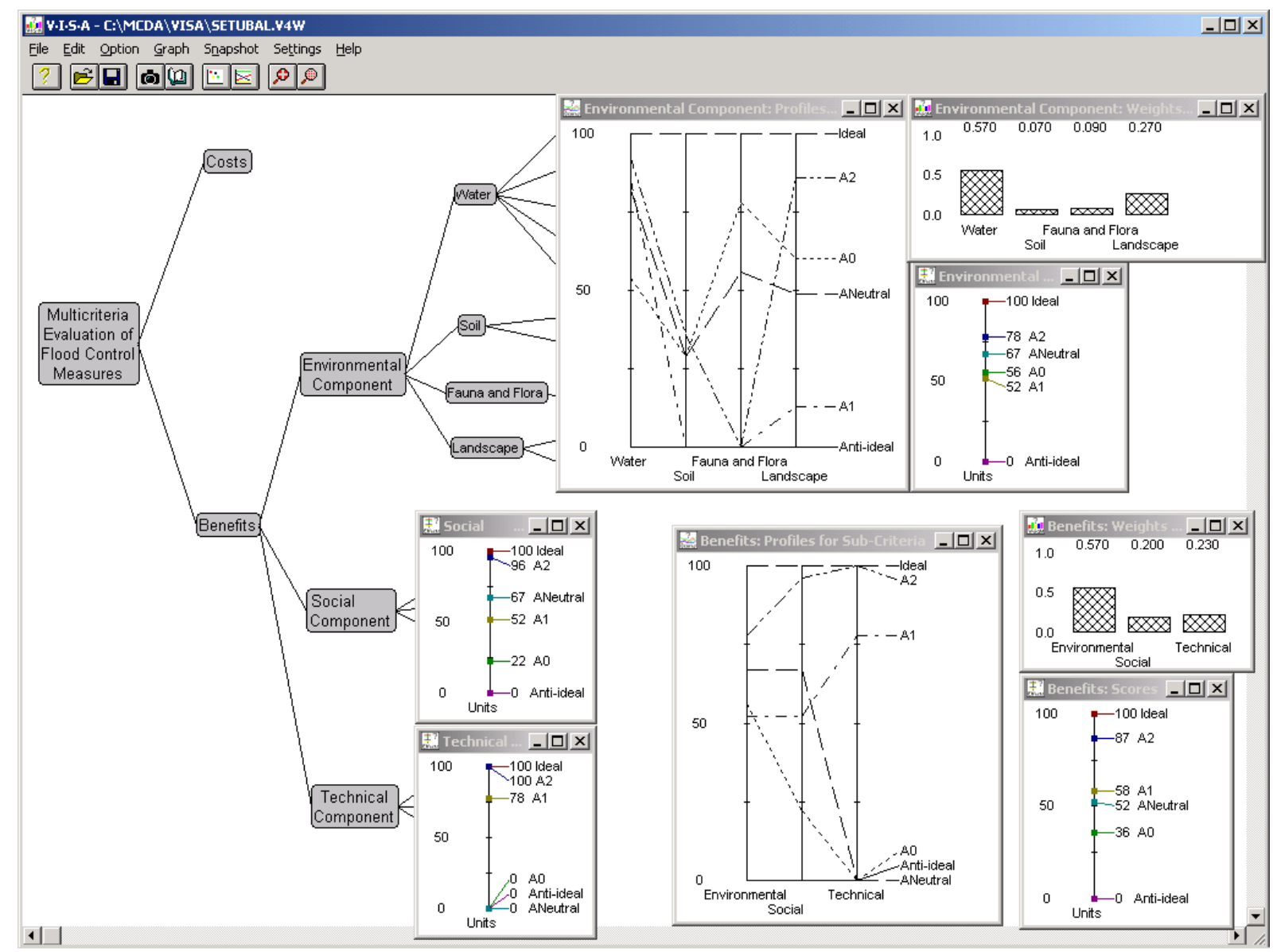

Figure $7 . \mathrm{V} \bullet \mathrm{I} \cdot \mathrm{S} \bullet \mathrm{A}$ analysis of the benefits of the options 


\subsection{Visual interactive sensitivity on the relative weights of the benefit components}

While discussing the requisiteness (cf. Phillips, 1984) of the multicriteria value model, a question was raised as to whether it would be reasonable to give the environment component a weight (0.57) that was greater than the weights of the social and technical components combined. As the graph displayed at the left in Figure 8 shows, the difference in overall benefit between $\mathrm{A} 1$ and $\mathrm{A} 0$ increases rapidly when the relative weight of the environment component decreases. In reality, A 1 is less attractive than A0 in the environmental component because A1 is a technical solution designed by the municipality's consultants to meet hydraulic concerns but without particular care for urban integration or landscape effects. Therefore, the low scores of A1 on "Landscape" and "Soil" are not (at all) surprising. It would, however, be necessary to unrealistically increase the weight of the environment component, by more than 0.25 , for the overall benefit of A0 to become greater than that of A1. All together, the three graphs in Figure 8 show that the overall benefit of A1 would always be significantly greater than the overall benefit of $\mathrm{A} 0$, for variations between -0.25 and +0.25 of the values given to relative weights of the three components. This undoubtedly justified the implementation of at least A1, so long as its total cost, estimated at $€ 1,6$ million, was considered to be acceptable.
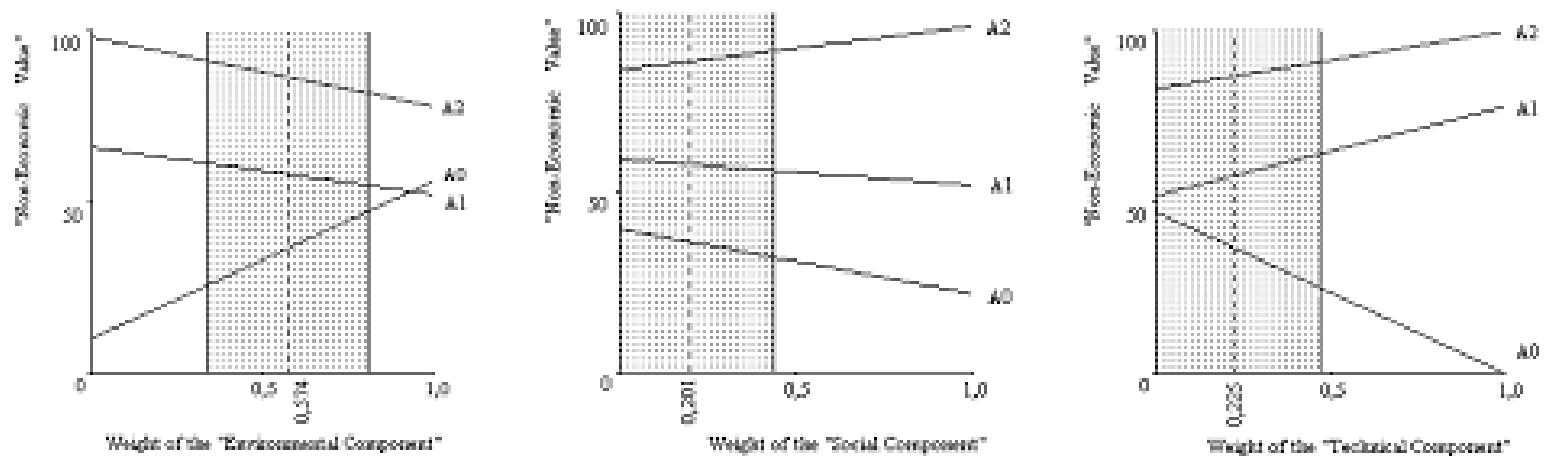

Figure 8. Sensitivity of the options' overall benefits to variations in the relative weight of each of the three main benefit components.

\subsection{Cost versus overall benefit analysis}

A trade-off between overall benefit and total cost would be necessary to decide whether or not the higher overall benefit provided by A2, relative to A1, compensates the significantly greater investment effort required (almost three times higher for A2 than for A1), as shown in the cost-benefit graph found in Figure 9. Note that this final analysis should be carried out along with the sensitivity of the overall scores for A2 and A1 against the variation of the weight given to the environmental component. Indeed, although the difference in overall benefit between $\mathrm{A} 2$ and $\mathrm{A} 1$ would not be affected by that weight, as can be seen by observing the left graph in Figure 8, the overall benefits of A2 and A1 would decrease significantly, and tend to approach that of $\mathrm{A} 0$, if the environmental component is given greater importance. 


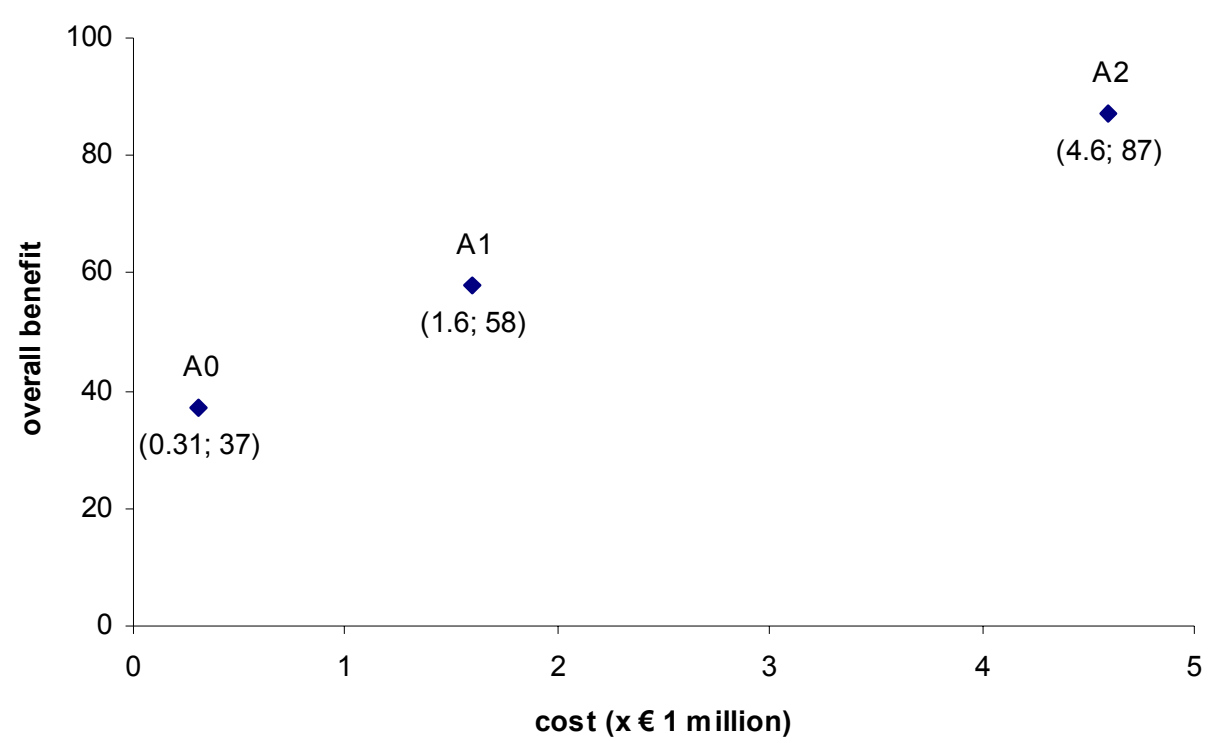

Figure 9. Cost-benefit analysis of the options.

\section{Conclusion}

Flood control measures cannot usually be evaluated from a single point of view. The technical performance of these measures, in terms of preventing inundation and the resulting damage, have to be weighted against social and environmental benefits that are also important for an overall appraisal of the acceptability of each alternative being considered. Interactive graphic displays of the various solutions and of their impacts are basic components of a decision support system for coping with flood control measures. As shown in previous articles (Correia et al., 1998a and 1999b), such a decision support system must be based on appropriate hydrological and hydraulic modelling coupled with a flexible GIS. However, the system is incomplete if it is not associated with an analysis that helps to measure the attractiveness of each solution with respect to the various relevant points of view. For this purpose, a well thought-out evaluation strategy should be conceived. Indeed, as stated by French $(1988$, p.337), "despite our natural inclination to believe in the ability of the human mind to make well-considered judgements and decisions, much evidence has been accumulated by many psychologists to make such a belief untenable. It appears that unguided, intuitive decision making is susceptible to many forms of inconsistency."

In principle, either a single-criterion or a multi-criteria decision aid methodology can be adopted to perform a structured multidimensional quantitative analysis, although their goals and usefulness depend on the decision context. It is worthwhile to emphasise that "the key conceptual distinction is between single criterion and multi-criteria approaches rather than single criterion and multi-criteria decisions" (Bana e Costa et al., 1997, p.30; see also Roy, 1996). This explains why an approach such as Cost-Benefit Analysis, as well as CostEffectiveness Analysis, could only erroneously be considered to be an MCDA approach; nevertheless, outputs of monetary-based analyses can be included, if appropriate, as elements in a MCDA process (as it was done in the Livramento case to estimate the costs of the intervention options). 
In a single-criterion approach such as the Cost Benefit Analysis (cf. Dasgupta and Pearce, 1972; Mishan, 1988) a single decision criterion, such as NPV, is constructed by monetary aggregation, under the assumption of a social welfare function. In the last three decades there has been a lively debate on the pros-and-cons of Cost Benefit Analysis applied to public policy evaluation and environmental assessment (cf. Munda, 1996; Bouyssou et al., 2000, chapter 5) giving rise to criticism of the need to reduce every decision's consequences to a monetary framework ( $c f$. Nijkamp, 1980, Sagoff, 1988); since the "economic valuation of environmental, socio-cultural and health effects, is quite difficult, sometimes impossible, and almost always questionable" (Nardini, 1998, p.200). This helps to explain why one can increasingly observe a move to MCDA in the public and government sectors ( $c f$. DETR, 2000) as well as environmental management ( $c f$. Janssen, 1994; Hobbs and Meier, 2000), and it is also one of the main reasons why an MCDA approach was adopted in the Livramento case. In MCDA, several independent evaluation criteria, either quantitative or qualitative, are constructed. Many MCDA approaches exist (cf. Gal et al., 1999; Belton and Stewart, 2002; Figueira et al., 2004) whose application to water resources management is not at all a recent event, as proved by the cases presented in (David and Duckstein, 1976), (Keeney and Wood, 1977), (Duckstein and Opricovic, 1979), or (Szidarovszly et al., 1986), to mention only a few. However, the one basic conviction underlying all of the MCDA approaches - multiattribute value and utility, outranking, goal and interactive multiobjective programming, etc. - is that the explicit introduction of several criteria, each representing a particular key point of view to be taken into account, "is a better path for robust decision making when facing multidimensional and ill-defined problems, than optimising a single objective function," such as NPV ( $c f$. Bana e Costa et al., 1997, p.30).

In the Livramento case, a number of uncertainties affected the appraisal of several consequences of the flood control measures. In spite of that, uncertainty was not considered to be a key issue requiring explicit formal modelling: the sensitivity analyses that were performed were deemed to be sufficient to take it into proper consideration. The key modelling concern was clearly the need to consistently assess the attractiveness of the alternatives against the significant number of benefit criteria that were identified. Two separate, although complementary, requirements were achieved: a measure of the partial attractiveness of each alternative against each criterion was derived from the analysis, and a multicriteria synthesis able to measure its overall attractiveness taking all of the benefit criteria jointly into consideration was created. The additive value model that was constructed is appropriate to evaluate any future flood control measure that might be proposed.

The MACBETH multicriteria approach followed to evaluate alternative flood control measures proved to be appropriate, flexible and sufficiently broad to be applied to other environmental problems. In particular, the experts involved in the MACBETH process considered it to be an appealing and straightforward device that helped them to learn about their own preferences, and appreciated its qualitative interactive question-answering protocol, which validates what Belton and Stewart (2002, p. 133) have stated about MACBETH: "The approach is a powerful one which can be effectively utilised if decision makers find the direct rating procedure difficult." The advantage of MACBETH for decision aiding, as modern MCDA in general, is not limited, therefore, to its technical ability to aiding in the construction of single value functions and the weighting of criteria. It should be seen in a much broader socio-technical scope. MCDA has evolved from a mechanism to rank alternatives, to a structured approach to organise factual and judgemental information and to argue logically about the pros-and-cons of the alternative courses of action. 
The ultimate goal of MACBETH is therefore to facilitate the process of learning about the problem and the alternatives, by enabling people to think about their values and preferences from several points of view. This goal was achieved in the Livramento case. Moreover, the study revealed:

$\checkmark$ The need for a decision support model that takes into consideration the environmental benefits of the alternatives, and that is suited for a participation-based decision-making process.

$\checkmark$ The ability of the proposed methodology to harmoniously integrate aspects of qualitative and quantitative nature in the same model.

$\checkmark$ The usefulness of building an analytical model that enables transparent and systematic comparison of the options, leading to soundly based support for the final choice.

In the case-study presented, only technical experts were consulted. They were, however, aware of the conclusions of a previous study (Correia et al., 1998b) in which particular attention was given to the population's perception of the consequences of the floods, and therefore incorporated this dimension along with other social concerns in the value tree (see Figure 4). In spite of that, direct consultation of the population involved and indirect consultation of the same population through representative associations, local authorities with a stake in the issue, and non-governmental associations (particularly environmental ones) should be part of a more extensive consultation process, giving rise, quite possibly, to several new dimensions of analysis or alternative solutions. In such a consultation process, a qualitative method like Stakeholder Analysis (cf. Burgoyne, 1994) and/or a problem structuring method ( $c f$. Mingers and Rosenhead, 2004) could be appropriately applied in the structuring phase and an open discussion about the value trade-offs implied by the weights attached to the criteria (see last line of Table 3) could enrich the phase of evaluation of the options, therefore enhancing the MCDA methodological framework proposed in this article. In any case, this methodology proved to be appropriate to support a complex decision-making process requiring the explicit consideration of a hide variety of environmental, social, technical and economic viewpoints.

\section{Acknowledgements}

The case-study presented in this paper was developed within the framework of the EUROflood Project sponsored by the European Commission, and also had the support of the Instituto Superior Técnico and the Instituto Superior de Agronomia of the Technical University of Lisbon, LNEC (National Laboratory for Civil Engineering), and CNIG (National Centre for Geographic Information). The authors also wish to thank all of the experts involved in the model building process for their invaluable collaboration, and Manuel Pedro Chagas and two anonymous referees for their valuable comments on an earlier version of this paper. 


\section{References}

Antão da Silva, P.A. (1996), Avaliação Multi-Critério de Medidas de Controlo de Cheias de um Ponto de Vista Ambiental, MSc Thesis, Instituto Superior Técnico, Lisbon.

Azibi, R., Vanderpooten, D. (2003), "Aggregation of dispersed consequences for constructing criteria: the evaluation of flood risk reduction strategies", European Journal of Operational Research, 144 (397-411).

Bana e Costa, C.A. (2001), " The use of multicriteria decision analysis to support the search for less conflicting policy options in a multi-actor context: case-study", Journal of MultiCriteria Decision Analysis, 10 (111-125).

Bana e Costa, C.A., Chagas, M.P. (2004), "A career choice problem: an example of how to use MACBETH to build a quantitative value model based on qualitative value judgments", European Journal of Operational Research, 153 (323-331).

Bana e Costa, C.A., Corrêa, E.C., De Corte, J.M., Vansnick, J.C. (2002), "Facilitating bid evaluation in public call for tenders: a socio-technical approach", OMEGA: The International Journal of Management Science, 30 (227-242).

Bana e Costa, C.A., De Corte, J.M., Vansnick, J.C. (2003), "MACBETH”, LSE OR Working Paper 03.56, London School of Economics, London.

Bana e Costa, C.A., De Corte, J.M., Vansnick, J.C. (2004), "On the mathematical foundations of MACBETH", in J. Figueira, S. Greco, M. Ehrgott (eds.), Multiple Criteria Decision Analysis: The State of the Art Surveys, Kluwer Academic Publishers, Dordrecht (forthcoming).

Bana e Costa, C.A., Pirlot, M. (1997), "Thoughts on the future of the multicriteria field: basic convictions and outline for a general methodology", in J. Clímaco (ed.), Multicriteria Analysis, Springer-Verlag, Berlin (562-568).

Bana e Costa, C.A., Stewart, T.J., Vansnick, J.C. (1997), "Multicriteria decision analysis: Some thoughts based on the tutorial and discussion sessions of the ESIGMA meetings", European Journal of Operational Research, 99 (28-37).

Bana e Costa, C.A., Vansnick, J.C. (1997), "Applications of the MACBETH approach in the framework of an additive aggregation model", Journal of Multi-Criteria Decision Analysis, 6 (107-114).

Bana e Costa, C.A., Vansnick, J.C. (1999), “The MACBETH approach: basic ideas, software, and an application", in N. Meskens, M. Roubens (eds.), Advances in Decision Analysis, Kluwer Academic Publishers, Dordrecht (131-157).

Beinat, E. (1997), Value Functions for Environmental Management, Kluwer Academic Publishers, Dordrecht.

Belton, V. (1999), "Multi-criteria problem structuring and analysis in a value theory framework", in T. Gal, T. Stewart, T. Hanne (eds.), Multicriteria Decision Making, Advances in MCDM: Models, Algorithms, Theory, and Applications, Kluwer Academic Publishers, Dordrecht (12-1-12-32).

Belton, V., Stewart, T.J. (2002), Multiple Criteria Decision Analysis: An Integrated Approach, Kluwer Academic Publishers, Dordrecht.

Belton, V., Vickers, S. (1990), "Use of a simple multi-attribute value function incorporating visual interactive sensitivity analysis for multiple criteria decision making", in C.A. Bana e Costa (ed.), Readings in Multiple Criteria Decision Aid, Springer-Verlag, Berlin (319334).

Bouyssou, D. (1990), "Building criteria: a prerequisite for MCDA", in C.A. Bana e Costa (ed.), Readings in Multiple Criteria Decision Aid, Springer-Verlag, Berlin (58-80). 
Bouyssou, D., Marchant, T. Pirlot, M., Perny, P. Tsoukiàs, A., Vincke, P. (2000), Evaluation and Decision Models: A Critical Perspective, Kluwer Academic Publishers, Dordrecht.

Burgoyne, J.G. (1994), "Stakeholder analysis", in C. Cassell and G. Symon (eds.), Qualitative Methods in Organizational Research: a Practical Guide, Sage Publications, London (187207).

Catalyze (2003), HIVIEW3 Starter Guide, Catalyze Ltd, London, 2003.

Correia, F.N., Castro Rêgo, F., Saraiva, M.G., Ramos, I. (1998a), "Coupling GIS with hydrologic and hydraulic flood modeling”, Water Resources Management, 12 (229-249).

Correia, F.N., Maureen, F., Saraiva, M.G., Bernardo, F. (1998b), "Flood hazard assessment and management: Interface with the public", Water Resources Management, 12 (209-227).

Correia, F.N., Saraiva, M.G., Silva, F.N., Bana e Costa, C.A., Ramos, I., Bernardo, F., Antão da Silva, P., Castro Rêgo, F. (1996), Innovative Approaches to Comprehensive Floodplain Management. A Framework for Participatory Valuation and Decision Making in Urban Developing Areas. Contribution for EUROflood 2 Project, Instituto Superior Técnico, Lisbon.

Correia, F.N., Saraiva, M.G., Silva, F.N., Ramos, I. (1999a), "Floodplain management in urban developing areas. Part I: Urban growth scenarios and land-use controls", Water Resources Management, 13 (1-21).

Correia, F.N., Saraiva, M.G., Silva, F.N., Ramos, I. (1999b), "Floodplain management in urban developing areas. Part II. GIS-based flood analysis and urban growth modeling", Water Resources Management, 13, (23-37).

Dasgupta, A.K., Pearce, D.W. (1972), Cost Benefit Analysis, Theory and Practice, MacMillan, London.

DETR (2000). Multi-Criteria Analysis: A Manual, Department of the Environment, Transport and the Regions, London.

David, L. Duckstein, L. (1976), "Multi-criterion ranking of alternative long-range water resources systems", Water Resources Bulletin, 12 (731-754).

Duckstein, L., Opricovic, S. (1979), "Multiobjective optimisation in river basin development", Water Resources Research, 16 (14-20).

Edwards, W. (1971), "Social Utilities”, Engineering Economist, Summer Symposium Series $6(119-129)$.

Edwards, W., Barron, F.H. (1994), "SMARTS and SMARTER: improved simple methods for multiattribute utility measurement", Organizational Behavior and Human Decision Processes, 60 (306-325).

Figueira, J. Greco, S., Ehrgott, M., editors (2004), Multiple Criteria Decision Analysis: The State of the Art Surveys, Kluwer Academic Publishers, Dordrecht (forthcoming).

French, S. (1988), Decision Theory: An Introduction to the Mathematics of Rationality, Ellis Horwood Limited, Chichester.

Gal. T., Stewart, T.J., Hanne T., editors (1999), Multicriteria Decision Making: Advances in MCDM Models, Algorithms, Theory, and Applications, Kluwer Academic Publishers, Dordrecht.

Hidroquatro (1992), Bacia de Retenção de Cheias da Ribeira do Livramento, Vol. 1, MARN, Lisbon.

Hobbs, B.F., Meier, P. (2000), Energy Decisions and the Environment: A Guide to the Use of Multicriteria Methods, Kluwer Academic Publishers, Dordrecht.

Janssen, R. (1994), Multiobjective Decision Support for Environmental Management, Kluwer Academic Publishers, Dordrecht.

Keeney, R.L. (1992), Value-Focused Thinking: A Path to Creative Decisionmaking, Harvard University Press, Cambridge, MA. 
Keeney, R.L., Wood, E.F. (1977), “An illustrative example of the use of multiattribute utility theory for water resources planning, Water Resources Research, 13 (705-712).

Kirkwood, C.W. (1996), Strategic Decision Making: Multiobjective Analysis with Spreadsheets, Duxbury Press, London.

Mingers, J., Rosenhead, J. (2004), "Problem structuring methods in action", European Journal of Operational Research, 152 (530-554).

Mishan, E.J. (1988), Cost-Benefit Analysis, Alan and Unwin, London.

Munda, G. (1996), "Cost-benefit analysis in integrated environmental assessment: some methodological issues", Ecological Economics, 19 (157-168).

Nardini, A. (1998), "Improving decision-making for land-use management: key ideas for an integrated approach based on MCA negotiation forums", in E. Beinat, P. Nijkamp (eds.), Multicriteria Analysis for Land-Use Management, Kluwer Academic Publishers, Dordrecht (197-223).

Nijkamp, P. (1980), Environmental Policy Analysis, Wiley, New York.

Penning-Rowsell, E. (1997), Improving Flood Hazard Management Across Europe, Final Report of EUROflood 2 Project, Flood Hazard Research Centre, Middlesex University, Enfield.

Penning-Rowsell, E., Fordham, M. (1994), Floods Across Europe, Hazard Assessment, Modelling and Management, Middlesex University Press, London.

Phillips, L.D. (1984), “A theory of requisite models”, Acta Psychologica, 56 (29-48).

Rosenhead, J. (1996), "What's the problem: an introduction to problem structuring methods", Interfaces, 26 (117-131).

Roy, B. (1996), Multicriteria Methodology for Decision Aiding, Kluwer Academic Publishers, Dordrecht.

Sagoff, M. (1988), The Economy of the Earth, Cambridge University Press, Cambridge.

Szidarovszky, F., Gershon, M.E., Duckstein, L. (1986), Techniques for Multiobjective Decision Making in Systems Management, Elsevier, Amsterdam.

von Winterfeldt, D., Edwards, W. (1986), Decision Analysis and Behavioral Research, Cambridge University Press, New York.

Watson, S.R., Buede, D.M. (1987), Decision Synthesis, The Principles and Practice of Decision Analysis, Cambridge University Press, New York. 